TM-1432

9204.000

\title{
Meson West Beamline Spoiler Magnets Electrical Design and Test Report
}

\author{
A.T. Visser \\ Fermi National Accelerator Laboratory, Batavia, IL, 60510 U.S.A.
}

November 25, 1986 


\section{CONTENTS}

1. Summary

2. Physical Description

3. Coil Design

4. Measurement of the Average Magnetic Field

Strength in the Steel

5. Beam Hole Stray Field and Shielding

6. Acknowledgement

7. Figures 1 through 13 


\section{SUMMARY}

This note describes the construction of five spoiler magnets installed in the secondary beamline to the Meson West Experimental Hall (Exp. \#706). Tests have been performed to measure the magnetic field in the steel as a function of the excitation current. B versus I curves for each spoiler are included. The leakage field in the beam pipe through the spoiler steel was too high. Magnetic shields and reduced excitation are used to lower this leakage field to acceptable levels.

\section{PHYSICAL DESCRIPTION}

Figures 1, 2 and 3 summarize the overall dimensions of the spoiler magnets. They are quite large. Each spoiler magnet is assembled from distressed steel plates of various thicknesses in the order of $7.5^{n}$ to $11.5^{n}$. These plates are stacked together to form the spoiler steel assembly. The mating surfaces, where the flux crosses, are machined flat to reduce air gaps. An evacuated beam pipe is inserted through a bored hole in the spoiler steel (S1, S2) or inserted in a machined slot with a filler plug (S3, S4, S5).

It is very costly to machine the large pieces of steel flat. The Mechanical Group has been rather successful to keep air gaps to a minimum. However, here and there air gaps, in the order of several $\mathrm{mm}$, could be found especially at S2. The filler plug should also fit tightly to reduce the stray field in the beam pipe and allow good field distribution above and below the beam pipe. The excitation coil is installed close to the beam pipe for the best field distribution in that area. The magnetic properties of the steel and the size of the air gaps are always a question. The steel is not homogeneous and the gaps vary from place to place. Educated guesses have to be made to calculate the excitation required for about $17 \mathrm{KG}$ field in the area of the beam pipe. The average value of this field is later on checked by installing a loop of wire around the steel and integrating the change of flux resulting from a change in excitation current. For calculations of the excitation we will assume that the steel is "as hot rolled C1030", (Fig. 4) and that the total air gap crossed by the magnetic flux is 0.01 ". This is in reasonable agreement with measured results from previous designs (Ref. 1).

\section{COIL DESIGN}

It is the least expensive to run all five spoilers in series from one power supply. The number of turns in each coil can be chosen to yield the required field strength. Space limitations require the use of a water cooled coil. We can choose a current density of about $2500 \mathrm{~A} /$ inch $^{2}$ to keep the coil losses reasonable. Higher current densities can be used as long as we are willing to pay for the losses and cooling is adequate. The final choice for the coil conductor was booster cooper, because it was on hand at Fermilab. The properties of the booster cooper are shown below. 
BOOSTER COPPER

$$
\begin{aligned}
& \mathrm{A}=0.153 \mathrm{in}^{2} \\
& \mathrm{~A}=0.9872 \mathrm{~cm}^{2} \\
& \mathrm{~W}=0.59 \mathrm{lbs} / \mathrm{ft} \\
& \rho_{20}=1.7241 \times 10^{-6} \mathrm{\Omega} \mathrm{cm}\left(\mathrm{at} 20^{\circ} \mathrm{C}\right) \\
& \rho_{60}=2 \times 10^{-6} \mathrm{\Omega m}\left(\text { at } 60^{\circ} \mathrm{C}\right) \\
& \mathrm{R}_{20} \approx 54.6 \times 10^{-6} \mathrm{n} / \mathrm{ft} \\
& \mathrm{R}_{60} \approx 63.4 \times 10^{-6} \mathrm{n} / \mathrm{ft}
\end{aligned}
$$

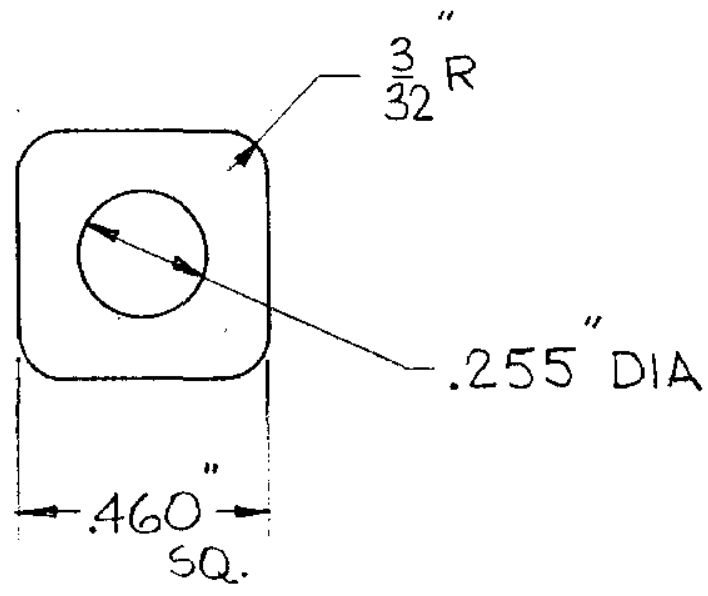

We will use an average operating temperature of $60^{\circ} \mathrm{C}$ for loss calculation. The conductor cross section is 0.153 in $^{2}$, which permits $0.153 \times 2500=382$ Amp DC $\max$.

We will initially choose an operating current of $350 \mathrm{Amp}$ DC, which can be supplied through one $500 \mathrm{MCM}, 90^{\circ} \mathrm{C}$ cable, rated $400 \mathrm{Amp}$ DC. It is now possible to calculate the number of coil turns, because we know the dimensions of the spoiler steel, the required field strength, the operating current and we have made reasonable assumptions for the type of steel and the air gaps.

We will calculate the required AmpereTurns for $17 \mathrm{KG}$ over the average iron length. Inside this loop the flux will be higher and outside, it will be lower. No adjustments are made for higher induction around the beam pipe area, since the effect is small and the errors resulting from steel and air gap assumptions could be much larger.

The average iron length through which the flux travels can be found from Fig. 1, 2 and 3. It takes 70 Oersteds or 5600 AmpereTurns per meter or $142 \mathrm{AT} /$ inch to drive $17 \mathrm{KG}$ through the iron (from Fig. 4).

The $0.01^{\prime \prime}$ air gap requires:

$$
\begin{aligned}
& \mathrm{NI}_{\text {air }}=\frac{1.7}{4 \pi \times 10^{-7}} \times 0.01 \times 2.54 \times 10^{-2} \\
& \mathrm{NI}_{\text {air }} \sim 350 \mathrm{AT} \text { at } 17 \mathrm{KG} / 0.01^{\mathrm{n}}
\end{aligned}
$$

Make the following table: 


\begin{tabular}{|c|c|c|c|c|c|c|c|}
\hline $\begin{array}{l}\text { Spoiler } \\
\text { Magnet }\end{array}$ & $\begin{array}{l}\text { Average } \\
\text { Iron } \\
\text { Length } \\
\text { at } 17 \mathrm{KG} \\
\text { INCH }\end{array}$ & $\begin{array}{l}\mathrm{NI}_{\text {iron }} \\
\mathrm{AT}\end{array}$ & $\begin{array}{l}\mathrm{NI}_{\text {air }} \\
0.01 \text { in. } \\
\mathrm{AT}\end{array}$ & $\begin{array}{l}\mathrm{NI}_{\text {total }} \\
\mathrm{AT}\end{array}$ & $\begin{array}{l}\text { Minimum } \\
\text { Required } \\
\text { Coil } \\
\text { Turns } \\
\text { at } 350 \text { A } \\
\text { N }\end{array}$ & $\begin{array}{l}\text { Chosen* } \\
\text { Coil } \\
\text { Turns } \\
\text { N }\end{array}$ & $\begin{array}{l}\text { Final** } \\
\text { Choice } \\
\text { Coil } \\
\text { Turns } \\
\text { N }\end{array}$ \\
\hline S1 & 322 & 45,724 & 350 & 46,074 & 132 & 132 & 68 \\
\hline S2 & 292.5 & 41,535 & 350 & 41,885 & 120 & 120 & 120 \\
\hline S3 & 94 & 13,348 & 350 & 13,698 & 39 & 40 & 20 \\
\hline S4 & 94 & 13,348 & 350 & 13,698 & 39 & 40 & 20 \\
\hline S5 & 94 & 13,348 & 350 & 13,698 & 39 & 40 & 20 \\
\hline
\end{tabular}

* Coils are made in 4 layers. Coil construction is easier with chosen $\mathrm{N}$.

** Later on we will discover from tests, that it is better to operate S1, S3, S4 and S5 at half the number of coil turns, because the stray field in the air gap is too high. Coils have been constructed with the chosen number of coil turns, and modified in the field. Modification was fortunately very simple. 


\subsection{S1 Coil Design}

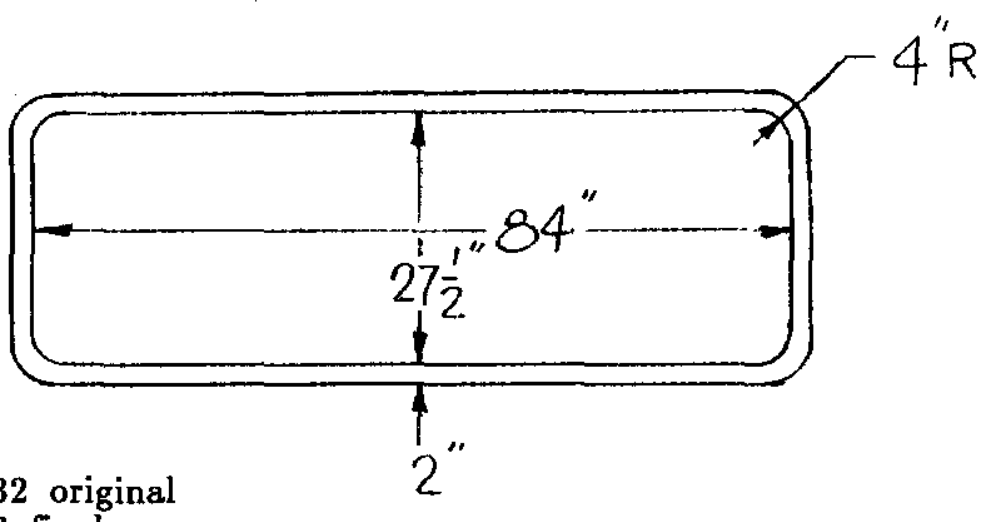

Turns

- 132 original

- 66 final

66 Turn Modif. $\quad 132 \mathrm{~T}$ Original

Average turn length

235 inch 235

$\mathrm{Cu}$ length

$2585 \mathrm{ft}$

2585

$\mathrm{Cu}$ weight

1525 lbs

1525

$\mathbf{R}_{60}$

$41 \times 10^{-3}$ ก

$164 \times 10^{-3} \Omega$

$\mathrm{V}_{60,350 A}$

14.4 Volt

57.4

$\mathrm{KW}_{60,350 \mathrm{~A}}$

$5 \mathrm{KW}$

20.1

0.5 GPM

2

Assume available $\Delta \mathrm{P}$

in tunnel at spoiler

100 PSI

100

Estimated flow (4 par.

circuits) at $100 \mathrm{psi}$

2.7 GPM

2.7

Coil temp rise $\Delta \mathrm{T}$

$7^{\circ} \mathrm{C}$

$28^{\circ} \mathrm{C}$

Insulation rating

$120^{\circ} \mathrm{C}$

$120^{\circ} \mathrm{C}$

Choose:

Coil Cross Section

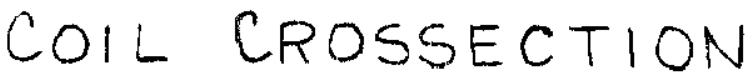

4 PARA:-EL WATER

CIRCUITS

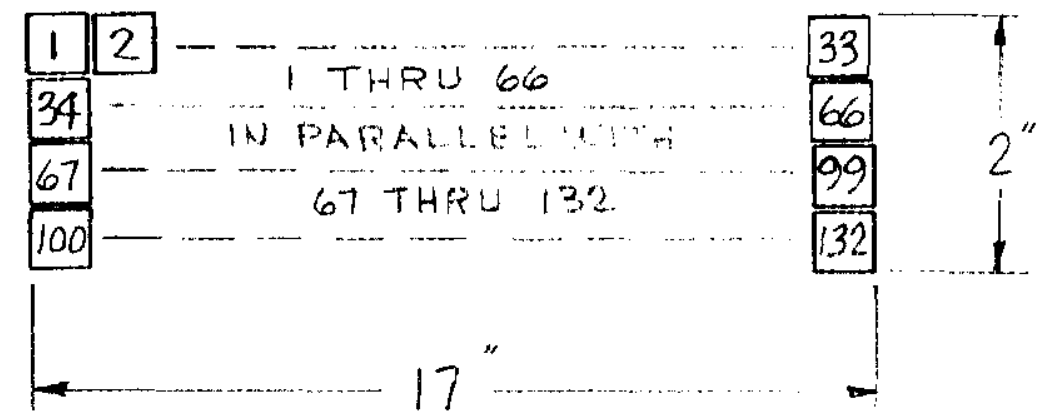




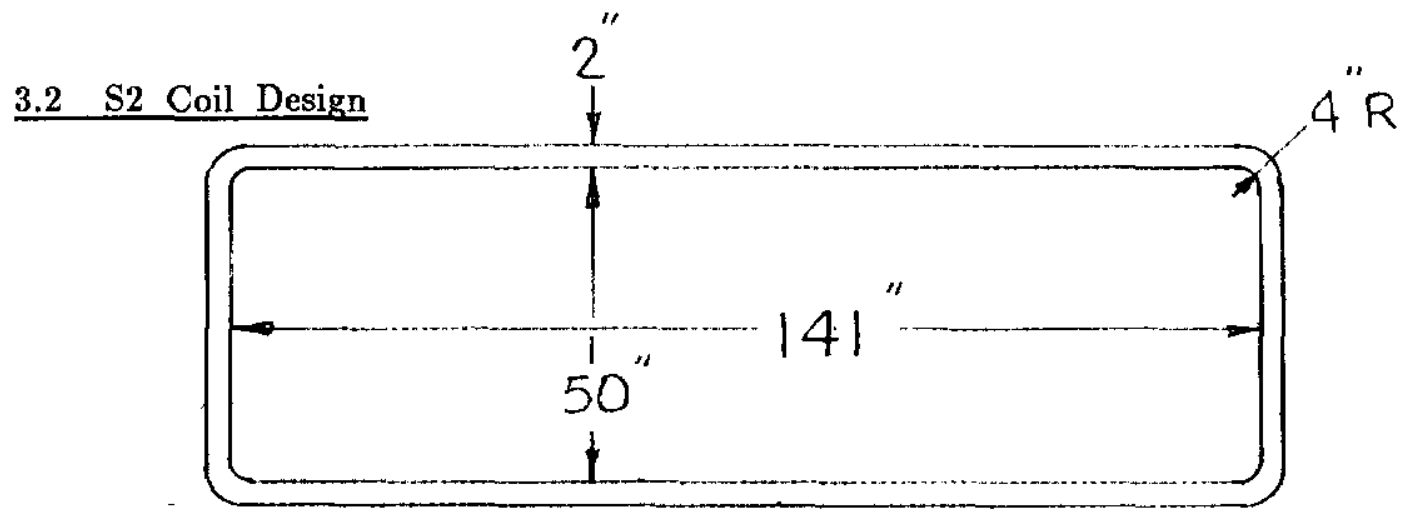

Turns

Average turn length

$\mathrm{Cu}$ length

$\mathrm{Cu}$ weight

$\mathbf{R}_{60}$

$\mathrm{V}_{60,350}$

$\mathrm{KW}_{60,350}$

Req'd flow for $\Delta T=38^{\circ} \mathrm{C}$

$\Delta P$

Flow (4 par. circuits at

$$
\Delta \mathrm{P}=100 \mathrm{psi})
$$

Coil temperature rise $\Delta \mathrm{T}$

Insulation rating
120

394 inch

$3940 \mathrm{ft}$

2325 lbs

$250 \times 10^{-3} \mathrm{\Omega}$

$87.4 \mathrm{~V}$

$30.6 \mathrm{KW}$

3 GPM

100 PSI

2 GPM

$58^{\circ} \mathrm{C}$

$120^{\circ} \mathrm{C}$

\section{Choose:}

\section{Coil Cross Section}

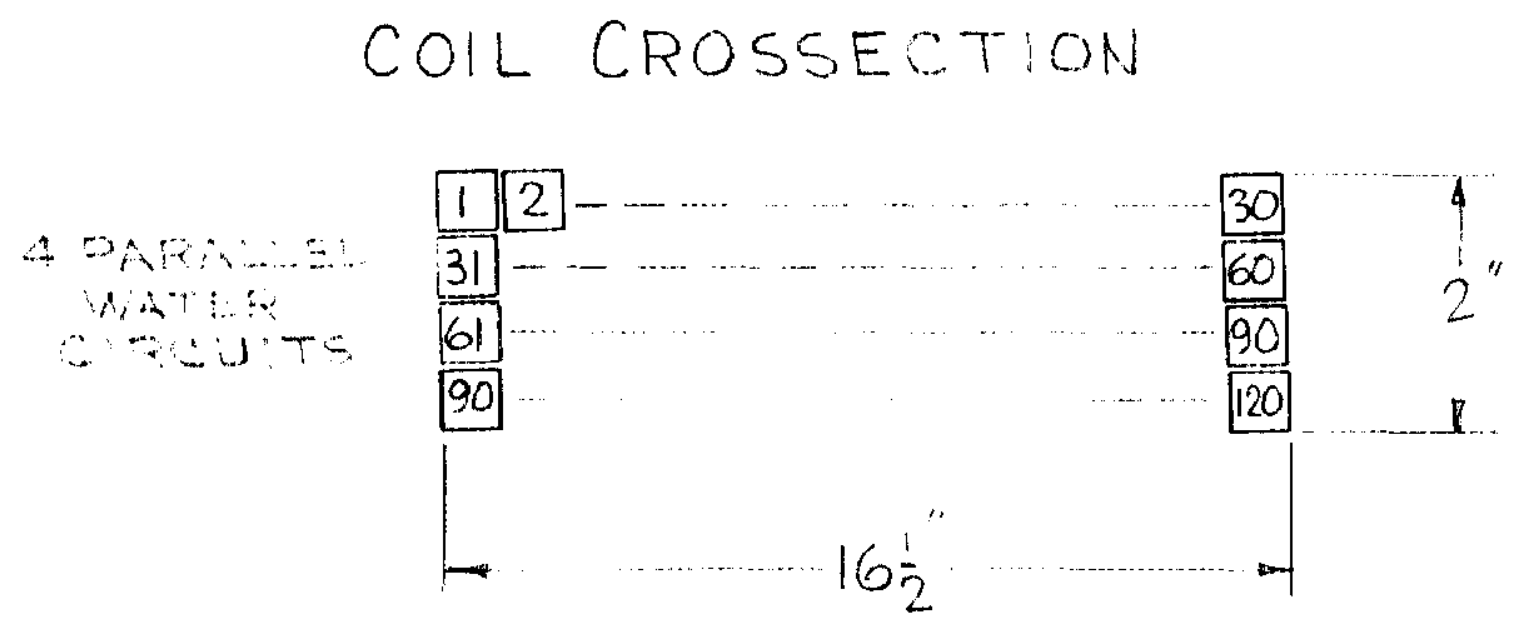


$3.3 \quad$ S3, S4 Coil Design (two identical coils)

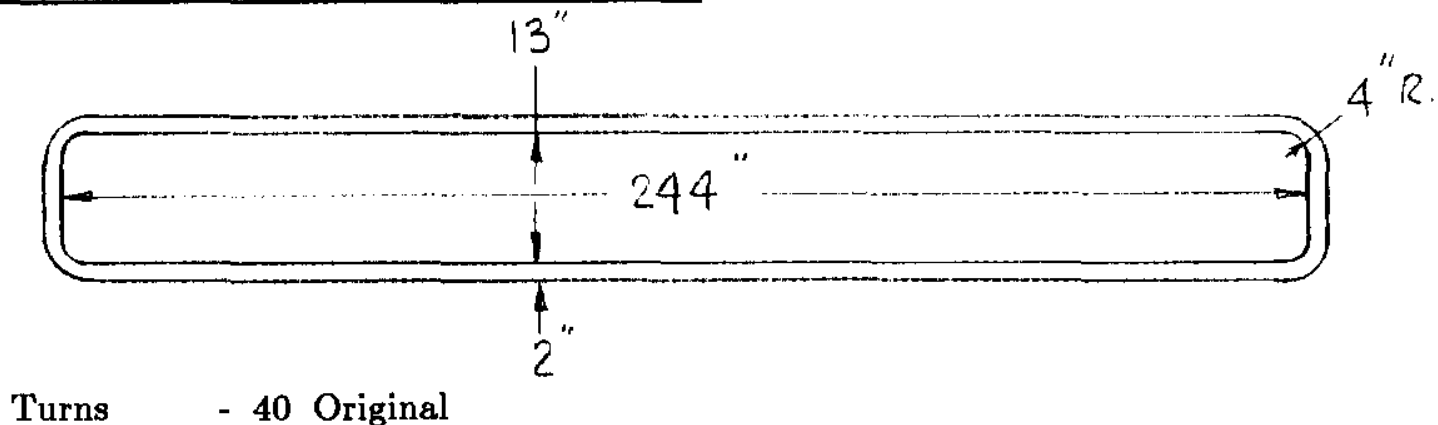

- 20 Final

Average turn length

$\mathrm{Cu}$ length

$\mathrm{Cu}$ weight

$\mathrm{R}_{60}$

$\mathrm{V}_{60,350}$

$\mathrm{KW}_{60,350}$

Req'd flow for $\Delta \mathrm{T}=38^{\circ} \mathrm{C}$

$\Delta P$

Est. flow (4 par. circuits at $100 \mathrm{psi}$ )

Coil temperature rise $\Delta \mathrm{T}$

Insulation rating
20 Turn Modif. 522 inch

$1740 \mathrm{ft}$

1027 lbs

$27.5 \times 10^{-3}$ ก

$9.6 \mathrm{~V}$

$3.5 \mathrm{KW}$

0.4 GPM

100 PSI

3.2 GPM

$4^{\circ} \mathrm{C}$

$120^{\circ} \mathrm{C}$
40 Turn Orignal

522

1740

1027

$110 \times 10^{-3}$

38.6

13.5

1.4

100

3.2

$16^{\circ}$

$120^{\circ}$

\section{Choose:}

\section{Coil Cross Section}

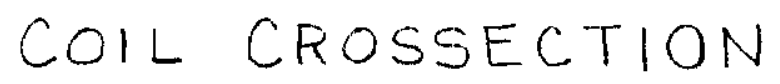

$$
\begin{gathered}
\text { A PARA-EL } \\
\text { MANES } \\
\text { IPCUIS }
\end{gathered}
$$
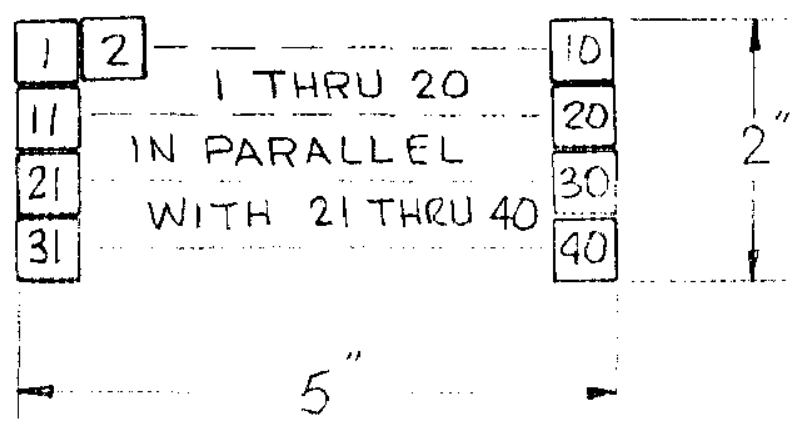
$3.4 \quad$ S5 Coil Design

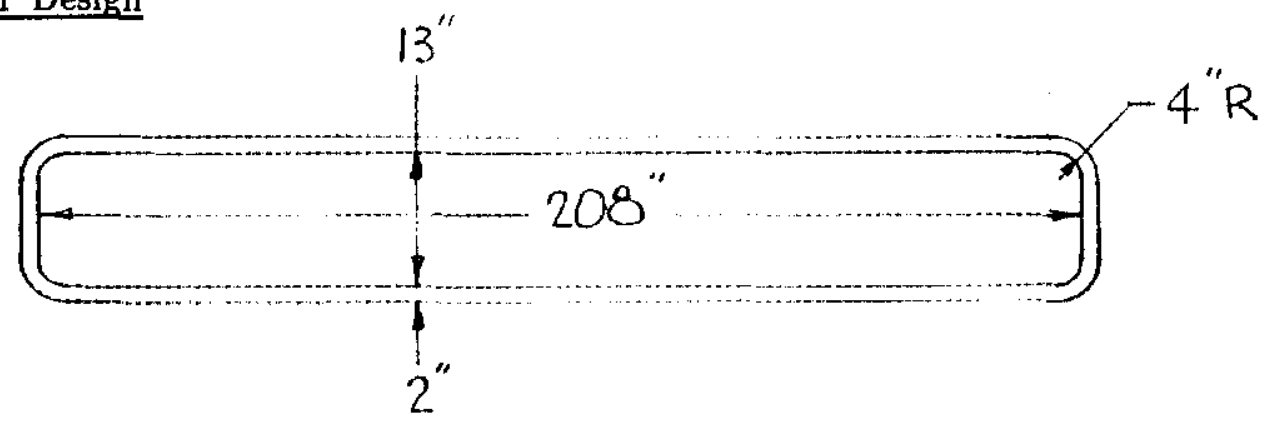

Turns $\quad-40$ original

- 20 final

\begin{tabular}{|c|c|c|}
\hline & 20 Turn Modif. & 40 Turn Original \\
\hline Average turn length & 450 inch & 450 \\
\hline $\mathrm{Cu}$ length & $1500 \mathrm{ft}$ & 1500 \\
\hline $\mathrm{Cu}$ weight & $885 \mathrm{lbs}$ & 885 \\
\hline $\mathbf{R}_{60}$ & $23.8 \times 10^{-3} \cap$ & $95.1 \times 10^{-3}$ \\
\hline$v_{60,350}$ & 8.3 Volt & $\mathbf{3 3 . 3}$ \\
\hline $\mathrm{KW}_{60,350}$ & $2.9 \mathrm{KW}$ & 11.6 \\
\hline Req'd flow for $\Delta \mathrm{T}=38^{\circ} \mathrm{C}$ & $0.3 \mathrm{GPM}$ & 1.2 \\
\hline$\Delta \mathrm{P}$ & 100 PSI & 100 \\
\hline
\end{tabular}

Est. flow (4 par. circuits at $100 \mathrm{psi}$ )

$\begin{array}{ll}3.2 \mathrm{GPM} & 3.2 \\ 3.4^{\circ} \mathrm{C} & 14^{\circ} \\ 120^{\circ} \mathrm{C} & 120^{\circ}\end{array}$

Coil temperature rise Insulation rating $120^{\circ} \mathrm{C}$ $120^{\circ}$

Choose:

Coil Cross Section

$$
\text { COIL CROSSECTION }
$$

4 PARALLEL WATER CIRCUITS 
3.5 Coil Summary

\begin{tabular}{|c|c|c|c|c|c|c|c|}
\hline Spoiler & $\begin{array}{l}\text { Turns } \\
\mathbf{N}\end{array}$ & $\begin{array}{l}\mathrm{Cu} \\
\mathrm{Ft}\end{array}$ & $\begin{array}{l}\mathrm{Cu} \\
\text { Lbs }\end{array}$ & $\begin{array}{l}100 \text { PSI } \\
\text { Calculated } \\
\text { Flow } \\
\text { GPM }\end{array}$ & $\begin{array}{l}100 \text { PSI } \\
\text { Measured } \\
\text { Flow } \\
\text { GPM }\end{array}$ & $\begin{array}{l}20^{\circ} \mathrm{C} \\
\text { Calculated } \\
\text { Resistance } \\
\times 10^{-3} \Omega\end{array}$ & $\begin{array}{l}\sim 20^{\circ} \mathrm{C} \\
\text { Measured } \\
\text { Resistance } \\
\times 10^{-3} \cap\end{array}$ \\
\hline S1 & 66 & 2585 & 1525 & 2.7 & 2.4 & 35.2 & 32.4 \\
\hline S2 & 120 & 3940 & 2325 & 2.0 & 2.2 & 215.1 & 204.0 \\
\hline S3 & 20 & 1740 & 1027 & 3.2 & 3.1 & 23.8 & 22.4 \\
\hline $\mathrm{S} 4$ & 20 & 1740 & 1027 & 3.2 & 3.3 & 23.8 & 22.7 \\
\hline S5 & 20 & 1500 & 885 & 3.2 & 3.6 & 20.5 & 19.6 \\
\hline TOTAL & -- & 11505 & 6789 & 14.3 & 14.6 & 318.4 & 301.1 \\
\hline
\end{tabular}

\begin{tabular}{|c|c|c|c|c|c|c|c|}
\hline Spoiler & $\begin{array}{l}\mathrm{I}^{*} \\
\text { Amp }\end{array}$ & $\begin{array}{l}\text { V } \\
\text { Volt } \\
60^{\circ} \mathrm{C}\end{array}$ & $\begin{array}{l}\text { Loss } \\
\mathrm{KW} \\
60^{\circ} \mathrm{C}\end{array}$ & $\begin{array}{l}100 \text { Psi } \\
\text { Temperature } \\
\text { Rise } \\
{ }^{\circ} \mathrm{C}\end{array}$ & $\begin{array}{l}\text { With } 40^{\circ} \mathrm{C} \\
\text { at Inlet } \\
\text { Max. Coil } \\
\text { Temperature } \\
{ }^{\circ} \mathrm{C}\end{array}$ & $\begin{array}{l}\text { Insulation } \\
\text { Rating } \\
{ }^{\circ} \mathrm{C}\end{array}$ & $\begin{array}{l}\text { Overtemp } \\
\text { Protection } \\
\text { Trip } \\
{ }^{\circ} \mathrm{C}\end{array}$ \\
\hline S1 & 350 & 14.4 & 5 & 7 & 47 & 120 & 80 \\
\hline S2 & 350 & 87.4 & 30.6 & 58 & 98 & 120 & $90^{*}$ \\
\hline S3 & 350 & 9.6 & 3.4 & 4 & 44 & 120 & 80 \\
\hline $\mathrm{S} 4$ & 350 & 9.6 & 3.4 & 4 & 44 & 120 & 80 \\
\hline S5 & 350 & 8.3 & 2.9 & 3.4 & 43.4 & 120 & 80 \\
\hline TOTAL & 350 & 130 & 45.3 & -- & -. & 120 & \\
\hline
\end{tabular}

* Final operating current is $250 \mathrm{~A}$. 
The flows in the above tables have been calculated from flow tables. The coil temperature rise has been calculated from:

$$
\Delta \mathrm{T}=\frac{\mathrm{KW} \times 3.8}{\mathrm{GPW}}{ }^{\circ} \mathrm{C}
$$

Coil S2 runs the hottest with a maximum temperature of $98^{\circ} \mathrm{C}$ at $350 \mathrm{ADC}$. However, operating currents in excess of $250 \mathrm{~A}$ give more than about 100 Gauss stray field in the beam pipe. This stray field should be limited to about 100 Gauss. An excitation current of $250 \mathrm{~A}$ yields on average the required $17 \mathrm{KG}$ field in the spoiler steel. The maximum operating temperature for S2 at $250 \mathrm{ADC}$ is $66^{\circ} \mathrm{C}$. Coil S2 might require a small booster pump for higher current operation.

3.6 Electrical Hookup, as Build

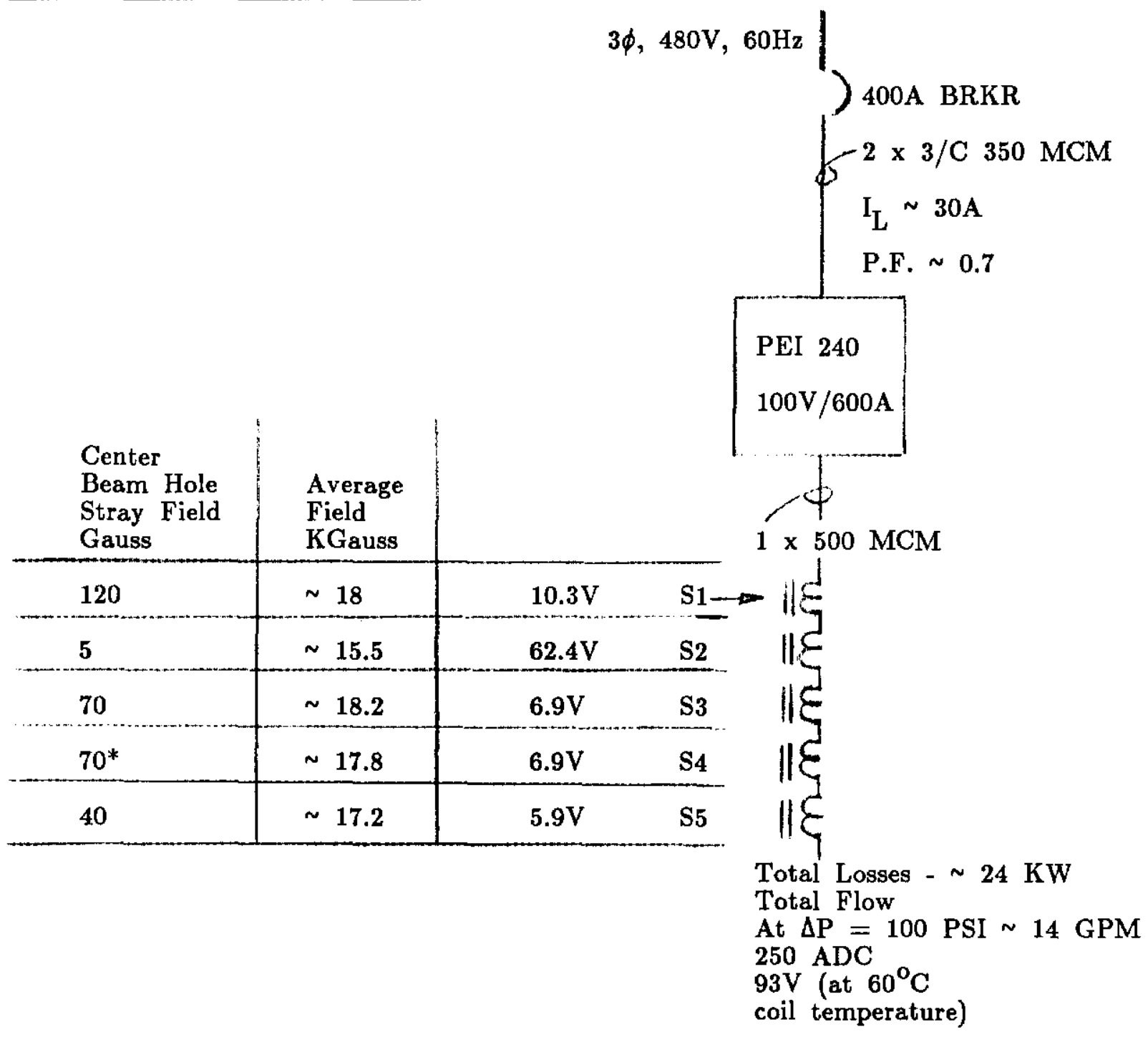

*Estimate same as S3. 


\section{MEASUREMENT OF THE AVERAGE FIELD STRENGTH}

\section{IN THE STEEL}

After the spoilers have been built the field in the steel must be measured. It is only practical to measure the average field in a chosen cross section of the steel as a function of excitation current. The areas above and below the beam pipe are chosen to be measured, since they are of the most interest.

The only way we can measure the field strength in a solid piece of excited steel, is to vary the excitation current and to integrate the resulting change in flux at a sense winding installed around the excited steel. It is a tedious method, which is described in detail in Ref. 1. The principle is briefly described hereafter.

Assume we have a steel toroid with cross section $\mathbf{A}$, in which we want to measure the field as a function of the excitation current $I$. A one turn sense winding is installed around $\mathrm{A}$.

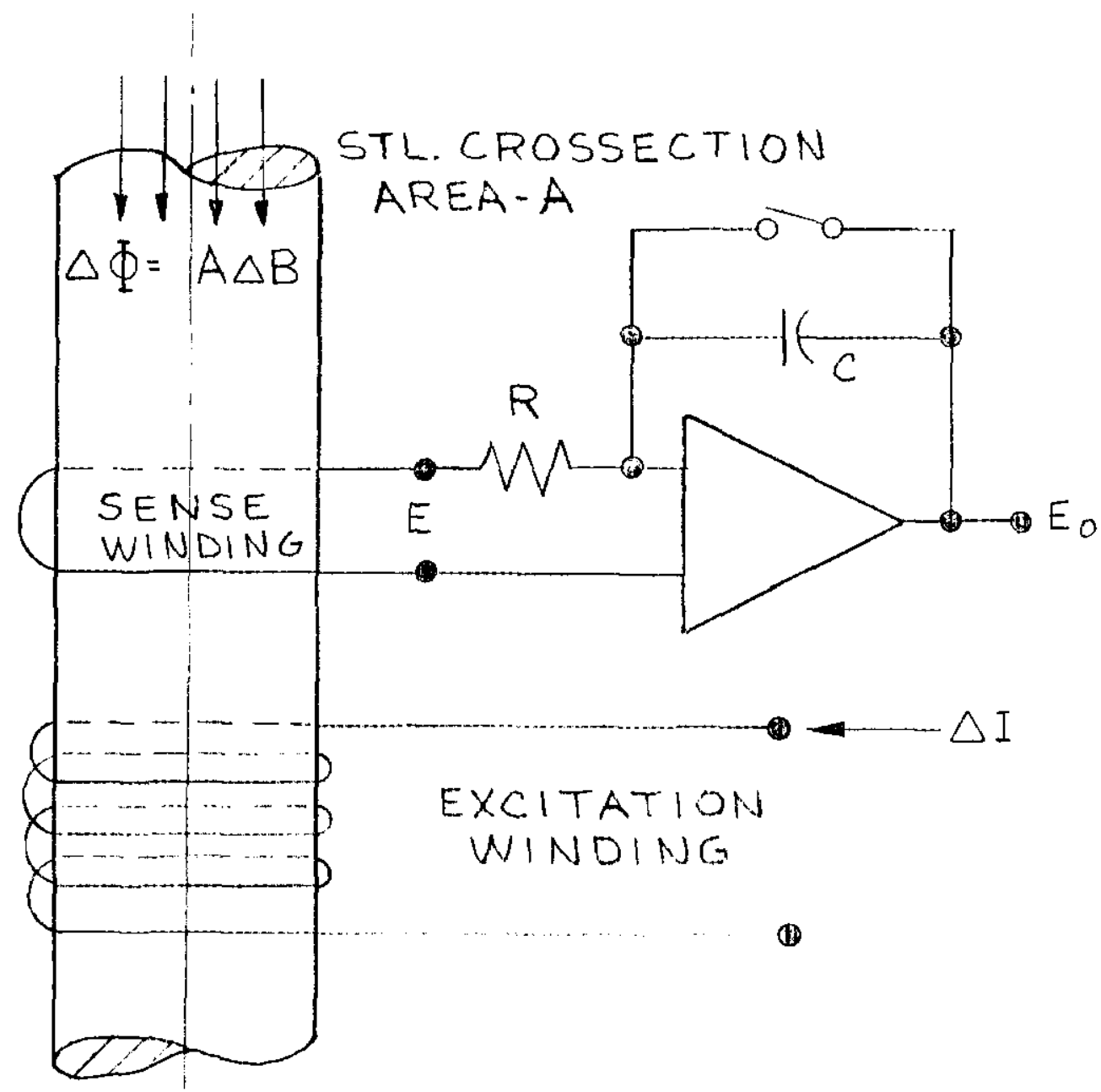

An excitation current change $\Delta \mathrm{I}$ will cause a flux change $\Delta \phi$, which induces a voltage $\mathrm{E}$ at the sense winding. The time integral of $E$ is collected at capacitor $C$ and appears as $\mathbf{E}_{0}$. 
For the one turn sense winding we can write:

$$
\begin{aligned}
& \mathrm{E}=-\frac{\mathrm{d} \phi}{\mathrm{dt}} \text { (resulting from current step } \Delta \mathrm{I} \text { ) } \\
& \int_{0}^{\mathrm{T}} \mathrm{Edt}=-\mathrm{A} \int_{0}^{\mathrm{T}} \mathrm{dB}
\end{aligned}
$$

for the integrator we can write:

$$
\begin{aligned}
& E_{0}=-\frac{1}{R C} \int_{0}^{T} E d t \\
& E_{0}=\frac{A}{R C} \int_{0}^{T} d B \\
& \int_{0}^{T} d B=\Delta B \\
& \Delta B=\frac{R C}{A} E_{0}
\end{aligned}
$$

We can calculate each $\Delta \mathrm{B}$ by multiplying the integrator output voltage $\mathrm{E}_{0}$ with constant RC/A, for each current change step $\Delta \mathrm{I}$. Keeping track of the cumulative ${ }^{\mathrm{o}}$ values of $\Delta \mathrm{I}$ and $\Delta \mathrm{B}$, and knowing that the $\mathrm{BH}$ curve is symmetrical around zero, allows the plotting of the $B$ versus I curve for the steel. The measurement is started by reversing the excitation current several times between positive and negative operating current values, which yields $B_{r}$ and $B$. The positive operating current is reduced in steps $\Delta I$ (yields $\Delta \mathrm{B}$ ) to zero, reversed quax $_{\mathrm{o}}$ minus operating current and brought to zero again, reversed and stepped up to the positive operating current, while recording $\Delta \mathrm{I}$ and $E_{o}$ for each step.

The value of the transfer constant RC/A should be known accurately.

$$
\Delta \mathrm{B}=\frac{\mathrm{RC}}{\mathrm{A}} \mathrm{E}_{\mathrm{O}} \mathrm{Wb} / \mathrm{m}^{2}
$$

is correct for:

$\mathrm{R}$ in Ohms

$C$ in Frads

$A$ in $\mathrm{m}^{2}$

$\mathrm{E}_{\mathrm{o}}$ in Volts 
or:

$$
\Delta \mathrm{B}=15.5 \frac{\mathrm{RC}}{\mathrm{A}} \mathrm{E}_{\mathrm{o}} \text { Gauss }
$$

is correct for:

$\mathrm{R}$ in Ohms
$\mathrm{C}$ in $\mu \mathrm{E}_{2} \mathrm{arad}$
$\mathrm{A}$ in in
$\mathrm{E}_{\mathrm{o}}$ in Volts.

The BH curves for spoilers S1 through S5 shown in Fig. 5 through 9 have been plotted from these measurements. The remnant field in the spoilers varies from 1 to $6 \mathrm{KG}$. Lower remnant fields are indicative of larger air gaps or different steel properties (Ref. 1). The curves only give the average field over the measured area and indicate that $250 \mathrm{~A}$ excitation yields about $17 \mathrm{KG}$ and operates the steel in the saturated region. Increasing the current above 250A does not increase the field in the steel much, but produces unacceptable (except for S2) stray field values in the beam pipe.

\section{BEAM HOLE STRAY FIELD AND MAGNETIC SHIELDING}

\subsection{Stray Field in the Beam Hole}

The spoiler magnets have a $3-1 / 2$ " round or square hole through the magnetized steel for the beam pipe. Ideally there should be no stray fields in the hole, but that is not the case, because the same number of AmpereTurns required to push the magnetic flux through the steel above and below the beam hole are also pushing flux (stray field) through the hole. When the steel around the beam hole becomes saturated, it requires many ampere turns and the stray field will increase much more rapidly than the field in the steel. Thus, high excitation in the steel can create unacceptably high stray fields. Stray fields in the order of 100 gauss are the upper acceptable limits, until operating results prove otherwise.

Now comes the question, "How much stray field can we expect and what can we do about it?" For the same steel it is obvious that a round hole has less stray field than a square hole with one side perpendicular to the field direction. A square hole with the field traveling in the direction of the diagonal would be better than the same hole in a different orientation. For economical reasons spoilers S1 and S2 have 3-1/2" diameter round holes and S3, S4 and S5 have 3$1 / 2$ " square holes, with one side perpendicular to the flux. This hole is made by milling a deep slot into the steel and then filling the top of the slot with a filler block, leaving a 3-1/2" square opening in the center of the steel. There are some small gaps associated with this, which require additional AmpereTurns, increasing the stray field even more, compared to solid steel around the hole. 
To drive 17 KGauss (see para. 3) through:

$$
\begin{aligned}
& \text { 3-1/2" steel requires } 500 \mathrm{AT} \\
& 0.01^{\text {" }} \text { air requires } \quad 350 \text { AT } \\
& \text { TOTAL }
\end{aligned}
$$

These same ampere turns appear across the beam hole.

1000 AT across the $3-1 / 2^{n}$ beam hole create about 140 Gauss stray field, as calculated below.

$$
\begin{aligned}
& \mathrm{B}=\mu \mathrm{H} \\
& \mathrm{B}=4 \pi \times 10^{-7} \times \frac{1000}{3.5 \times 2.54 \times 10^{-2}} \times 10^{4} \text { Gauss } \\
& \mathrm{B} \sim 140 \text { Gauss. }
\end{aligned}
$$

Increasing the steel induction to $20 \mathrm{KGauss}$ requires about 5 times as many AmpereTurns, which increases the stray field to an estimated value of 700 Gauss. These are all some pretty rough estimates, but it is reasonable to expect, at 17 KG steel field, stray fields in the order of 100 Gauss, which increase rapidly at higher induction. This estimate proved to be on the low side.

The stray field in the beam hole has been measured (at the center of the hole) and is plotted along with the spoiler excitation curves shown in Figs. 5 through 9. The plots show (curve \#3) stray fields in the order of 200 Gauss, except S5 is in the order of 100 Gauss, for about $17 \mathrm{KG}$ steel excitation. However, all spoiler magnets are operated in series and to make each one run at 17 KGauss or better, requires $250 \mathrm{~A}$ excitation. S2 does not make it, but runs at about 15.5 KGauss. S2 appears to have larger air gaps. This operating current gives a reasonable compromise between steel excitation and stray field, when a magnetic shield is used.

\subsection{Magnetic Shield for the Beam Hole}

Operation of the spoilers at $250 \mathrm{~A}$ produces stray fields substantially beyond 100 Gauss. A cylindrical shield made from transformer steel, which can support high fields can be inserted in the beam pipe as a magnetic shield. This material is relatively inexpensive and easily rolled to the required diameters. 
The thickness of the shield can be estimated by saying, that all the flux from the 3-1/2" hole side has to travel through the shield wall and not make anymore than $15 \mathrm{KG}$ in the shield wall. Suppose a uniform (1000 Gauss) field emits from the $3-1 / 2^{n}$ side and is all collected in the round shield wall with thickness $t$, at $15 \mathrm{KG}$. Then we can write:

$$
\begin{aligned}
& 3.5 \times 1000=2 \mathrm{t} \times 15000 \\
& \mathrm{t}=0.117^{\prime}
\end{aligned}
$$

This is a very simplistic approach, because as soon as the shield is inserted in the hole more flux will try to cross it by traveling through the shield wall and thus saturating it prematurely. This will make the shield ineffective. The further the shield is away from the hole walls, the better it works, but now it interferes with the beam aperture. It is clear that the shield should be inside the stainless steel beam pipe, preferably with some spacer. Figure 10 shows the results of various tests with different stray field shields at spoiler S3. The final shields were made from 10 layers, 12 mills thick oriented silicon steel, ARMCO M5. They are made in 6 inch lengths, degreased and not annealed at a cost of $\$ 7.15$ each. Twelve layers of 12 mill silectron steel seem to work some what better.

All spoiler magnets have been equipped with 10 layers, 10 mill M5 as shown in Fig. 11. All stray fields at $250 \mathrm{~A}$ are now about 100 Gauss or lower, compared to stray fields in the order of 1000 Gauss without shields. It should be understood that the stray fields have only been measured at one center point and might vary along the beam axis or away from the center.

This seems to be the best we can do without interfering with the beam aperture.

\section{ACKNOWLEDGEMENTS}

Toni Passi made all the mechanical work happen with the help of Don Carpenter. Our magnet factory made the coils. Walt Jaskierny and Julius Lenz made integrators and helped with the tests along with other technicians. Their help is much appreciated and was necessary to complete this job.

\section{REFERENCES}

TM978 - 6013.000 "A short approach to the electrical design of a muon spoiler", A.T. Visser, July 1980. 

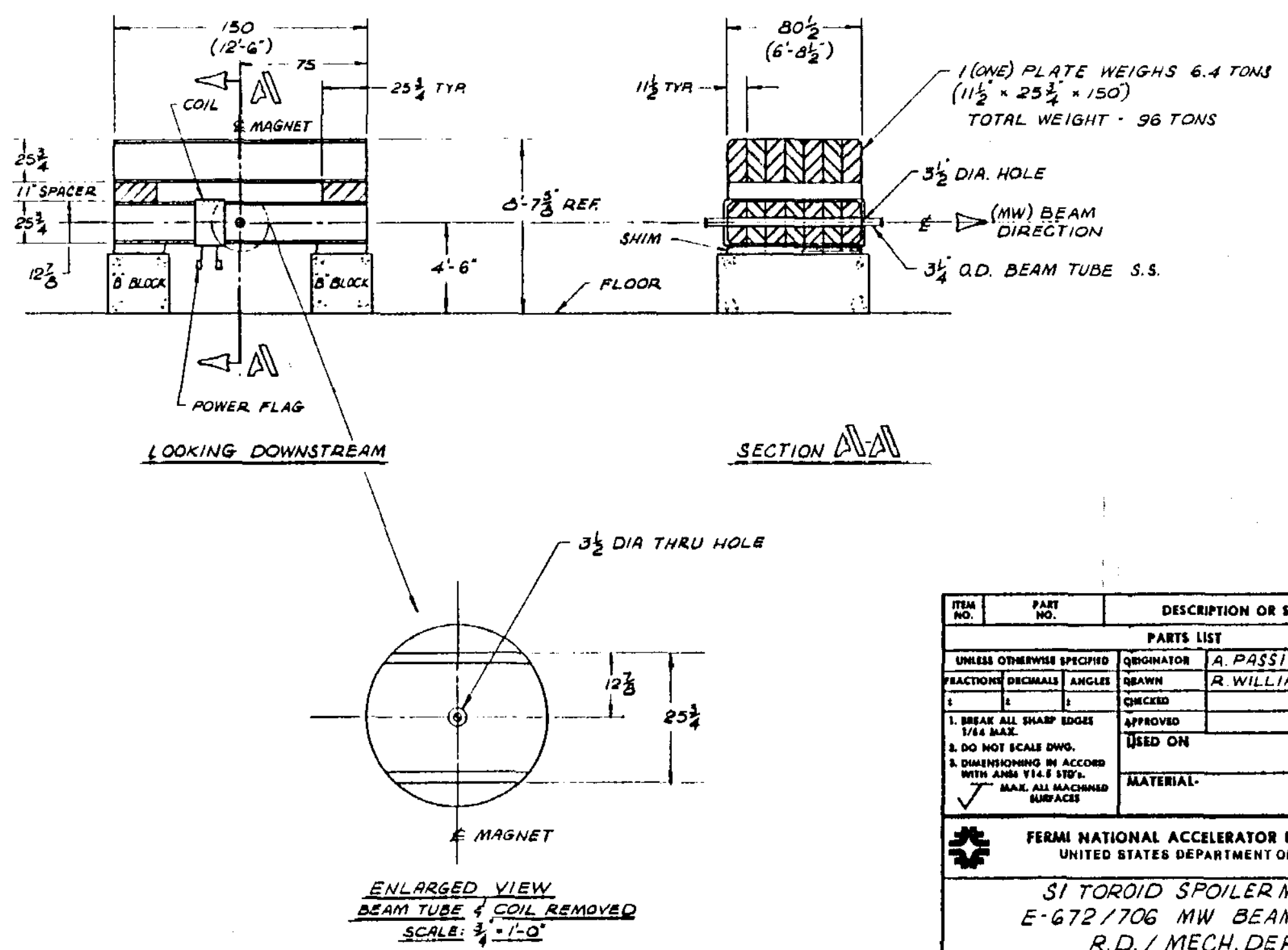

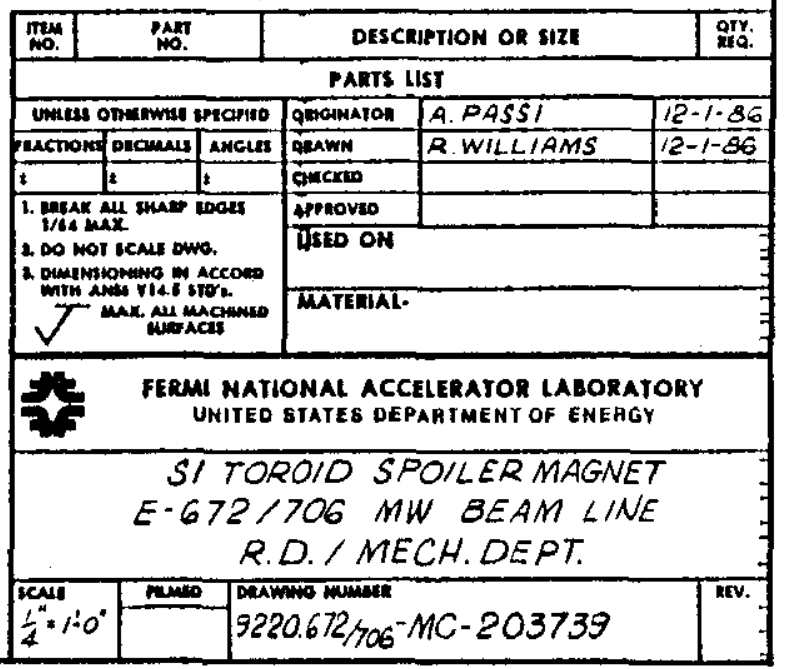




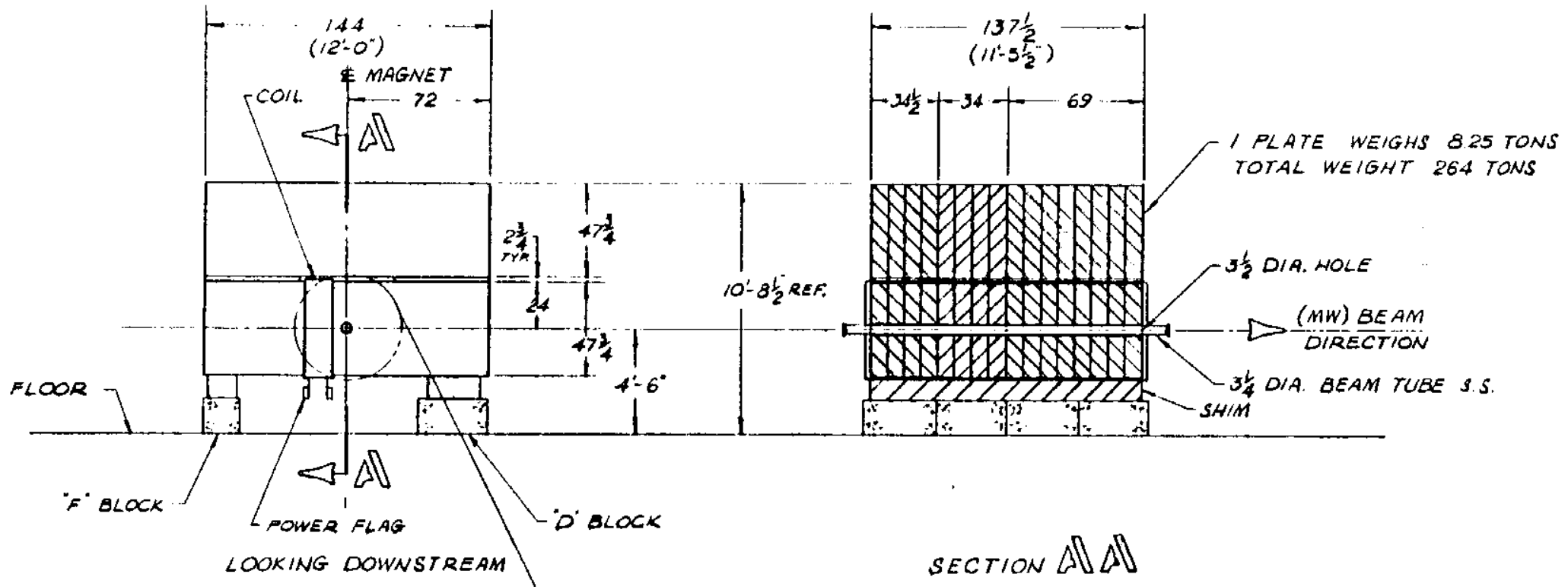

LOOKING DOWNSTREAM

SECTION ADAl

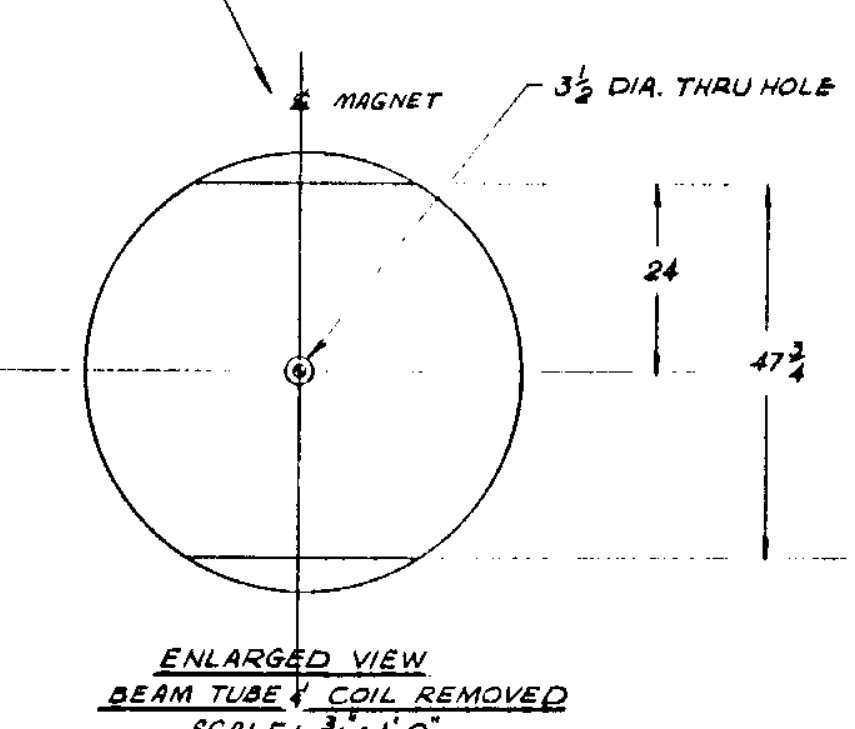

SCALE $3=1$ :O

$F / \theta 2$

\begin{tabular}{|c|c|c|c|c|}
\hline min. & , int? & DESC & IFTION OR SIZE & $998:$ \\
\hline \multicolumn{5}{|c|}{ PARTS LST } \\
\hline \multicolumn{2}{|c|}{ 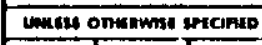 } & Ogigainaion & $A$ PASSI & $2-1.86$ \\
\hline \multirow{2}{*}{\multicolumn{2}{|c|}{ 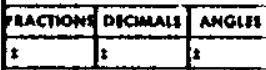 }} & DRAWN & R.W/LLIAMS & $12 \cdot 1 \cdot 36$ \\
\hline & & auckio & & \\
\hline \multirow{3}{*}{\multicolumn{2}{|c|}{ 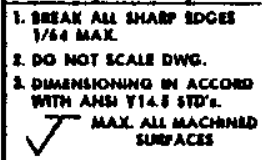 }} & Appinoves & & \\
\hline & & Uरक ON & & \\
\hline & & MATERIAL & & \\
\hline \multicolumn{5}{|c|}{$\begin{array}{l}\text { FERMI NATIONAL ACCELERATOR LABORAYORY } \\
\text { UMITED SIATES DEPARTMENT OF ENERGY }\end{array}$} \\
\hline \multicolumn{5}{|c|}{$\begin{array}{c}\text { S2 TORO/D (SPO/LER) MAGNET } \\
\text { E-672/706 MW BEAM LINE } \\
\text { R.D. / MECH. DEPT. }\end{array}$} \\
\hline & \begin{tabular}{|l|l}
$\operatorname{minsi}$ \\
92
\end{tabular} & $20.672 / 706^{-1}$ & $c-2037$ & तथv. \\
\hline
\end{tabular}



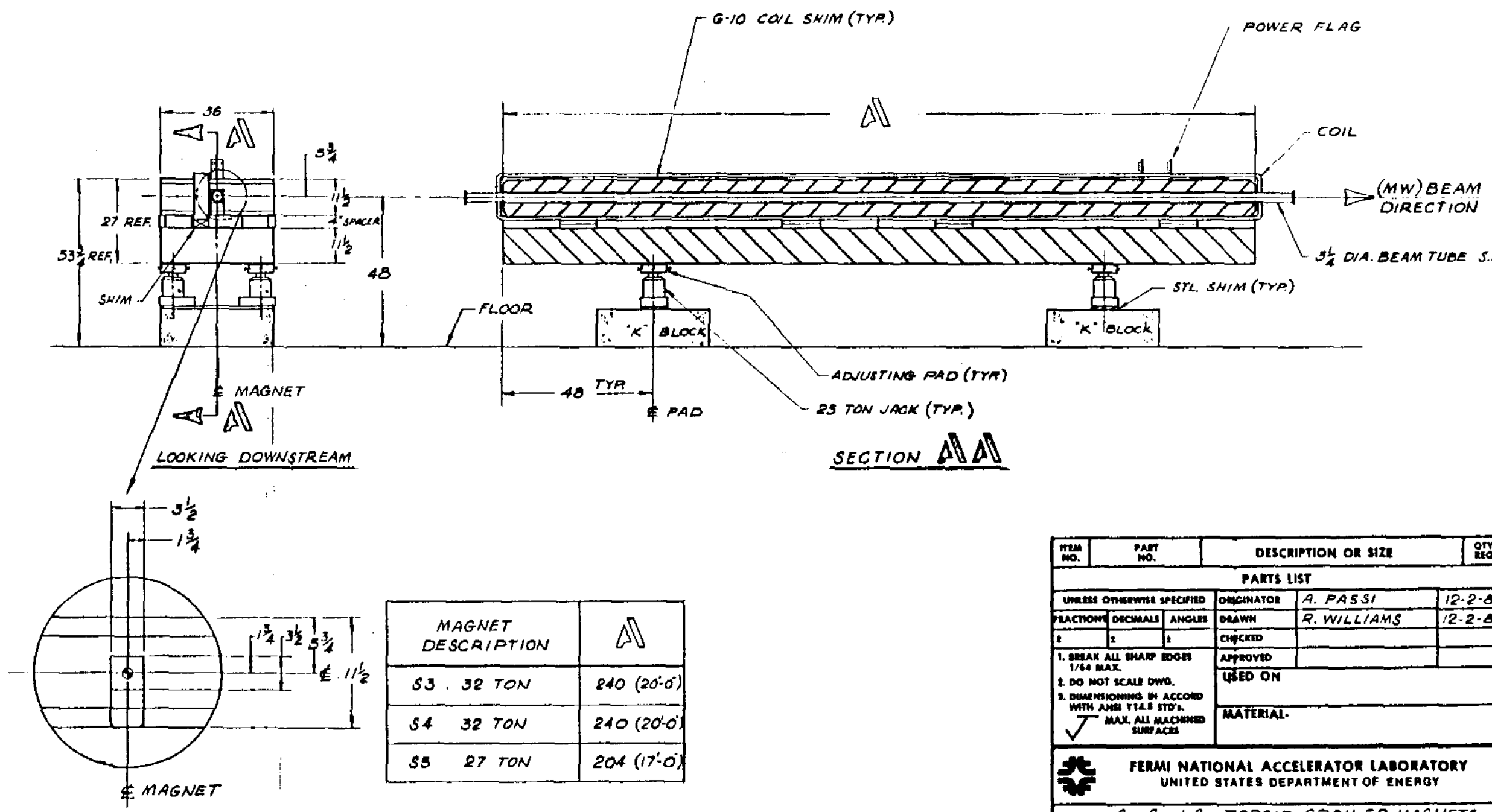

\begin{tabular}{|c|c|}
\hline $\begin{array}{c}\text { MAGNET } \\
\text { DESCRIPTION }\end{array}$ & AD \\
\hline S3 32 TON & $240\left(20^{\circ}-0^{\circ}\right)$ \\
\hline S4 32 TON & $210\left(20^{\circ}-0^{\circ}\right.$ \\
\hline SS 27 TON & $204\left(17^{\prime} \cdot 0^{\circ}\right)$ \\
\hline
\end{tabular}

ENLARGED VIEW BEAM TUBE L COIL REMOVED

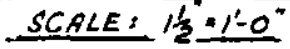

\begin{tabular}{|c|c|c|c|c|}
\hline m... & mon. & DEsC & IPTION OR Size & orro: \\
\hline \multicolumn{5}{|c|}{ PAKTS LIST } \\
\hline \multirow{2}{*}{\multicolumn{2}{|c|}{ 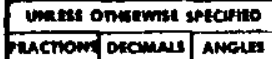 }} & Tomanaros & A. PASSI & $12 \cdot 2 \cdot 8$ \\
\hline & & Doenwiny & R.WILLIAMS & $\longdiv { 1 2 \cdot 2 \cdot \Delta 6 }$ \\
\hline & $E$ & sincoso & & \\
\hline \multirow{3}{*}{\multicolumn{2}{|c|}{ 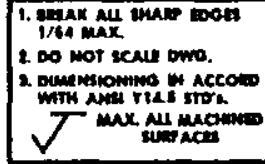 }} & NipNovesto & & \\
\hline & & \multicolumn{3}{|l|}{ TSEO ON } \\
\hline & & \multicolumn{3}{|l|}{ MATEARL- } \\
\hline & \multicolumn{4}{|c|}{$\begin{array}{l}\text { FERMI NATIONAL ACCELERATOR LALORATORY } \\
\text { UNITED STATES DEPAATMENT OF EMEAQY }\end{array}$} \\
\hline & \multicolumn{4}{|c|}{$\begin{array}{c}S_{3}, S_{4} / S_{S} \text { TOROID SPOILER MAGNETS } \\
E .672 / 706 \text { MW BEAM LINE } \\
\text { R.D. / MECH. DEPT. }\end{array}$} \\
\hline $\begin{array}{l}\text { send } \\
\frac{1}{2}+1\end{array}$ & 92 & \multicolumn{2}{|c|}{ 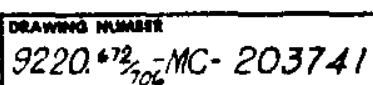 } & nav. \\
\hline
\end{tabular}




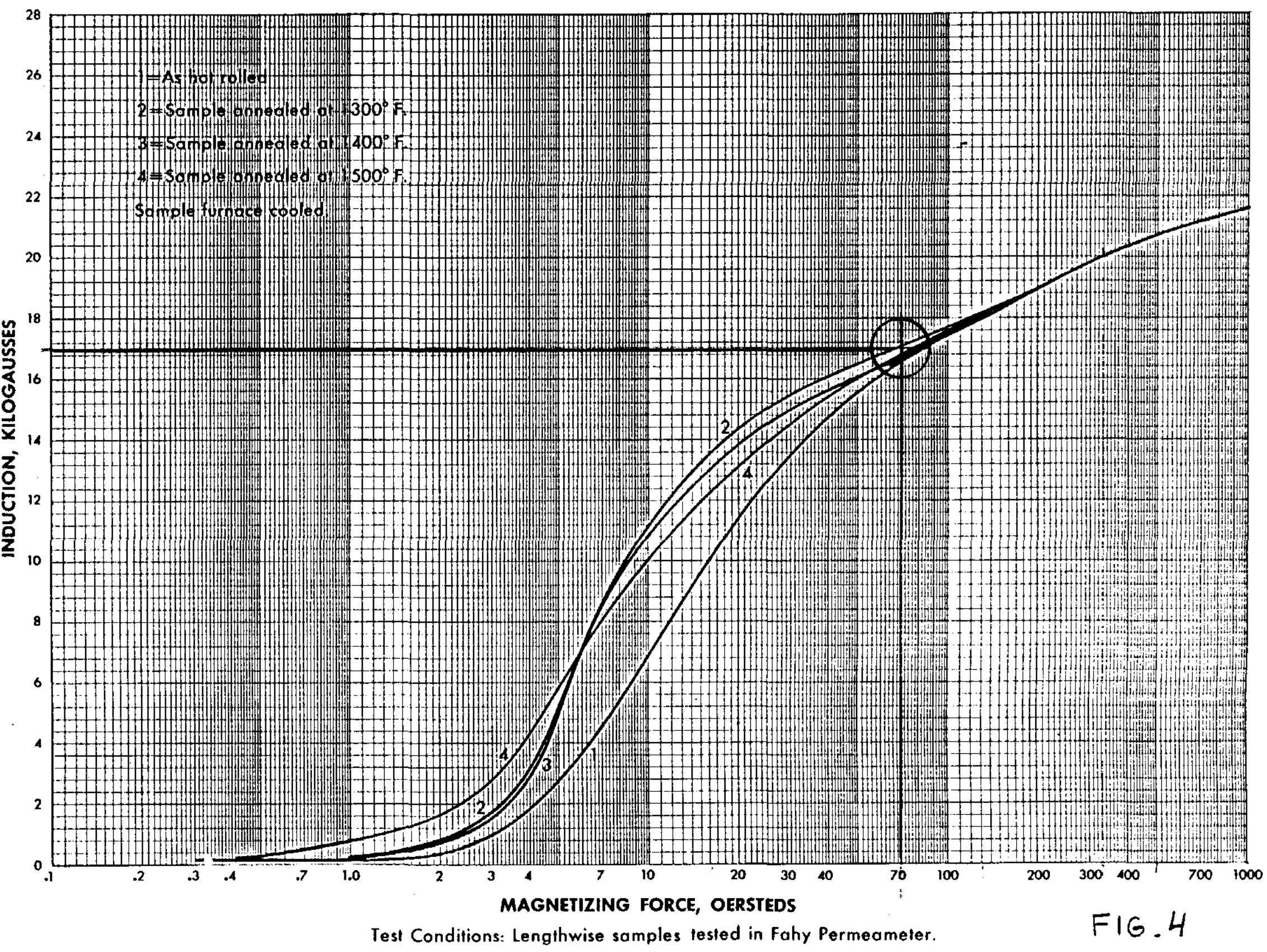




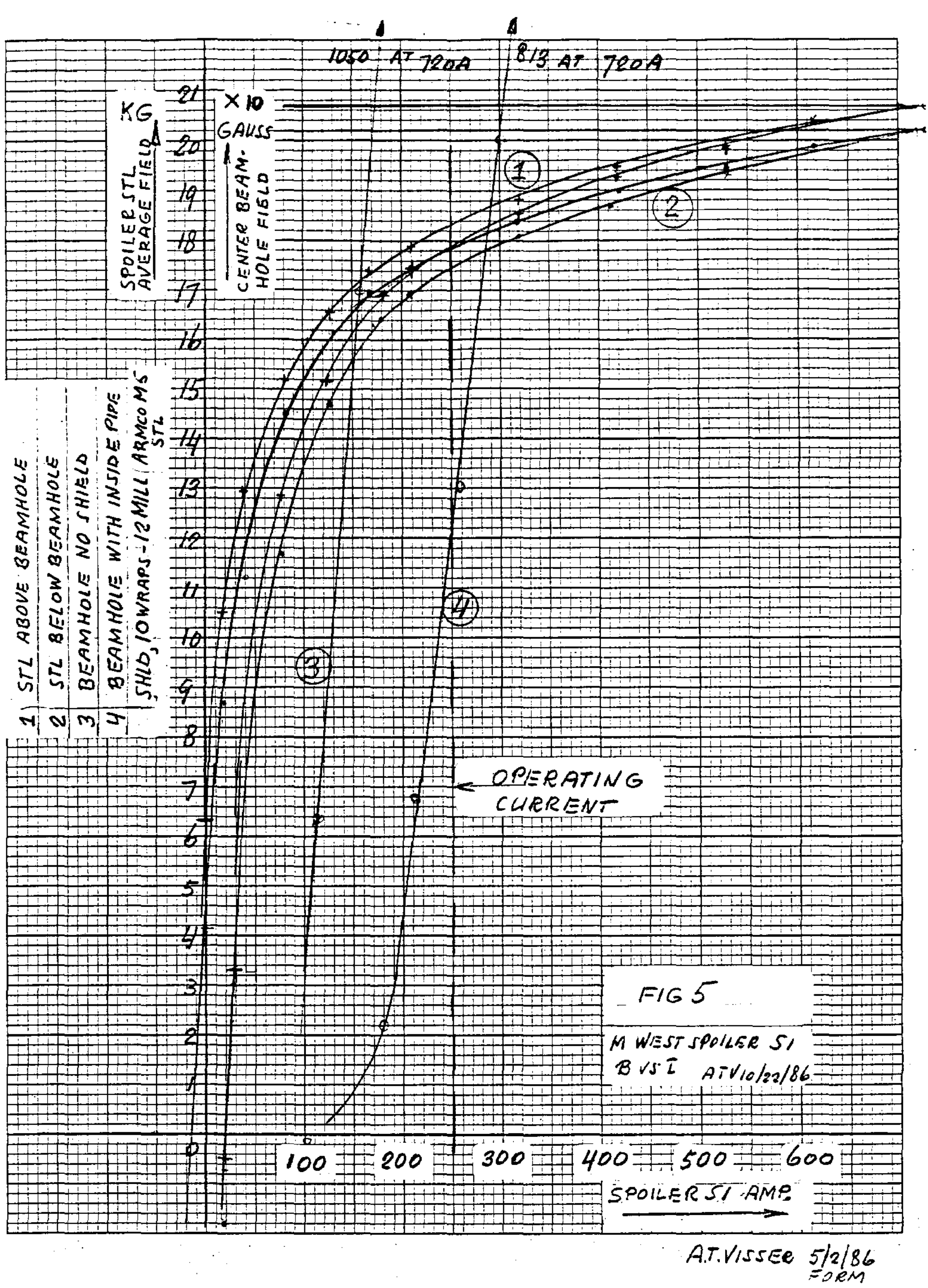




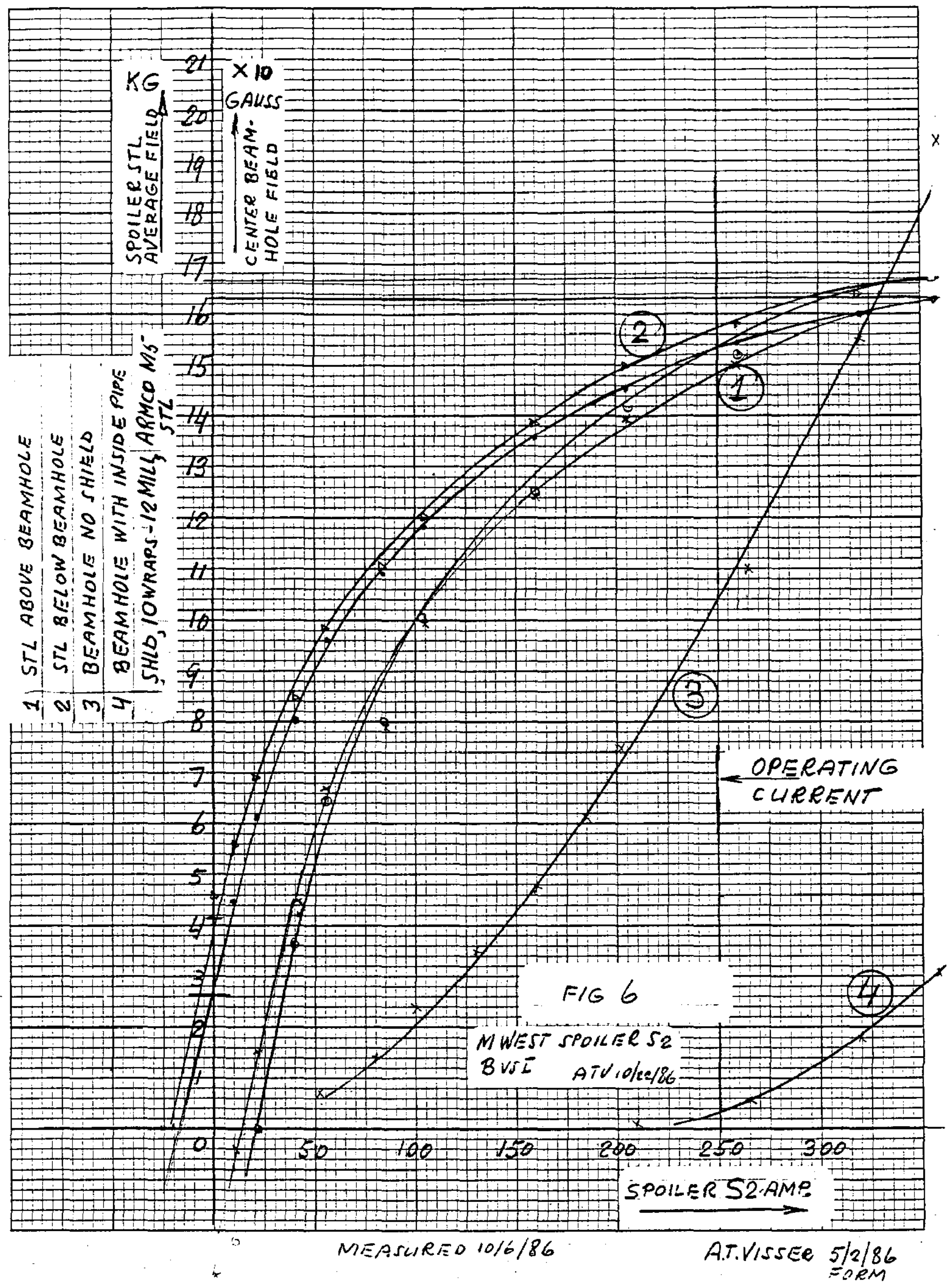




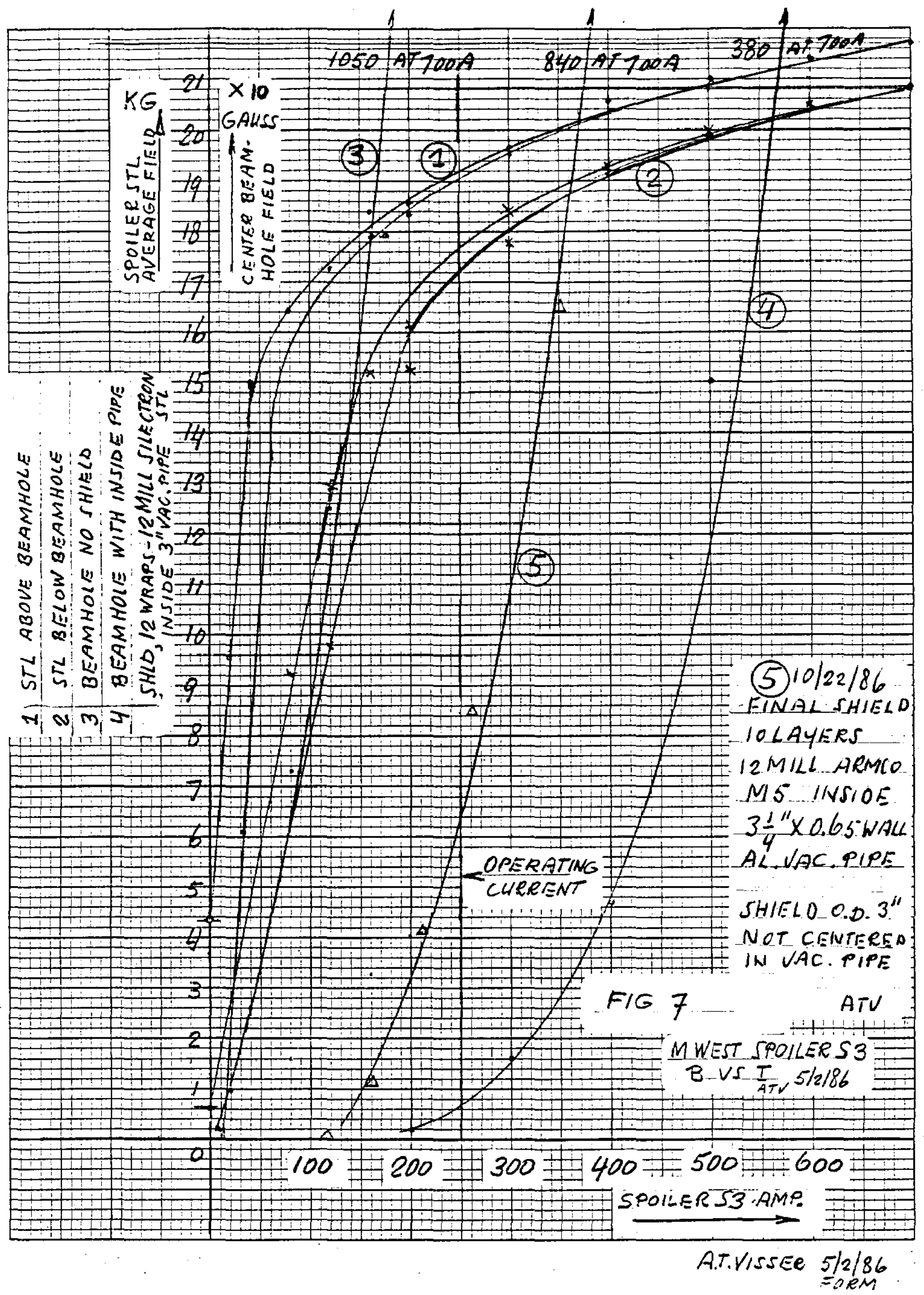




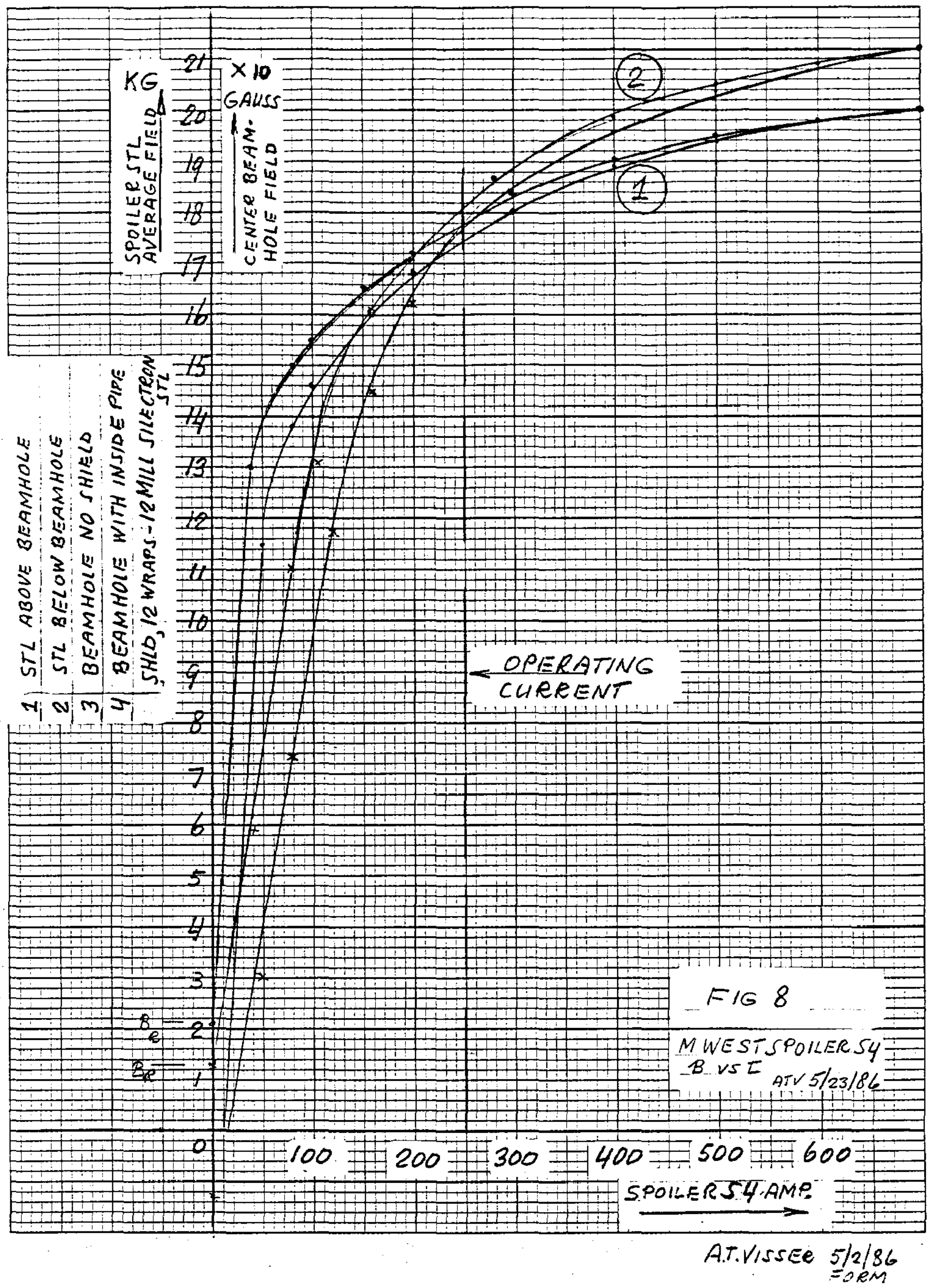




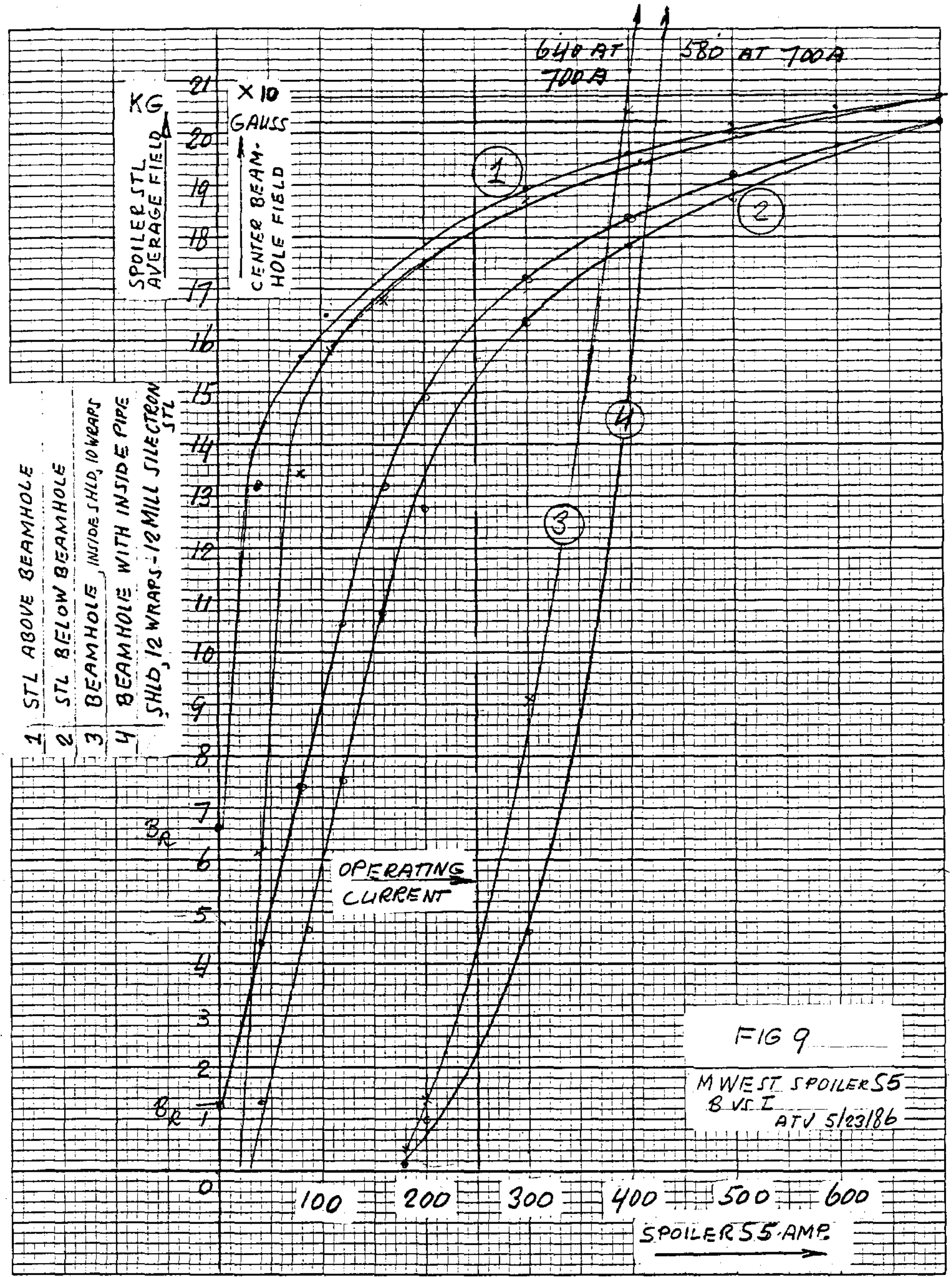




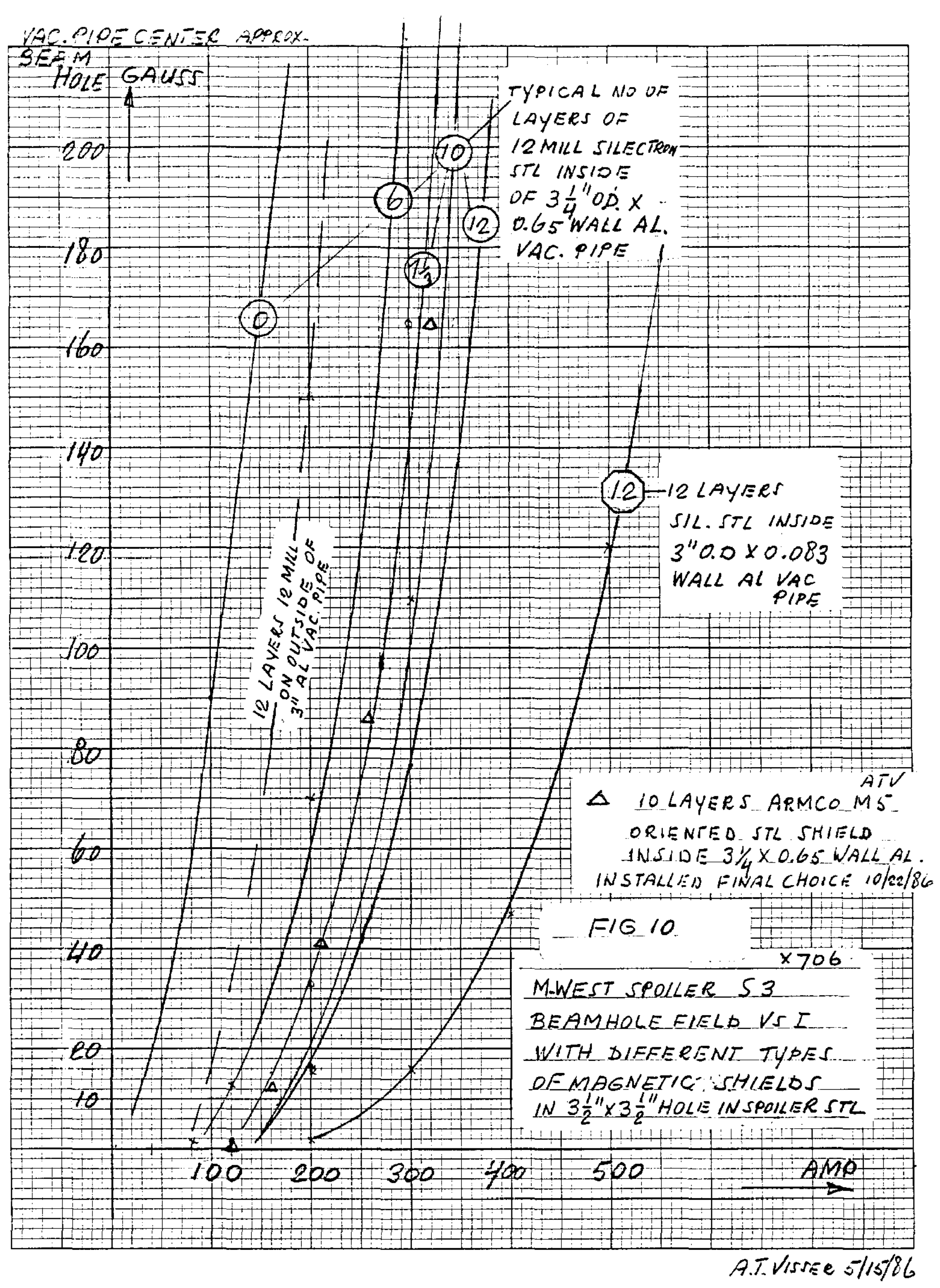




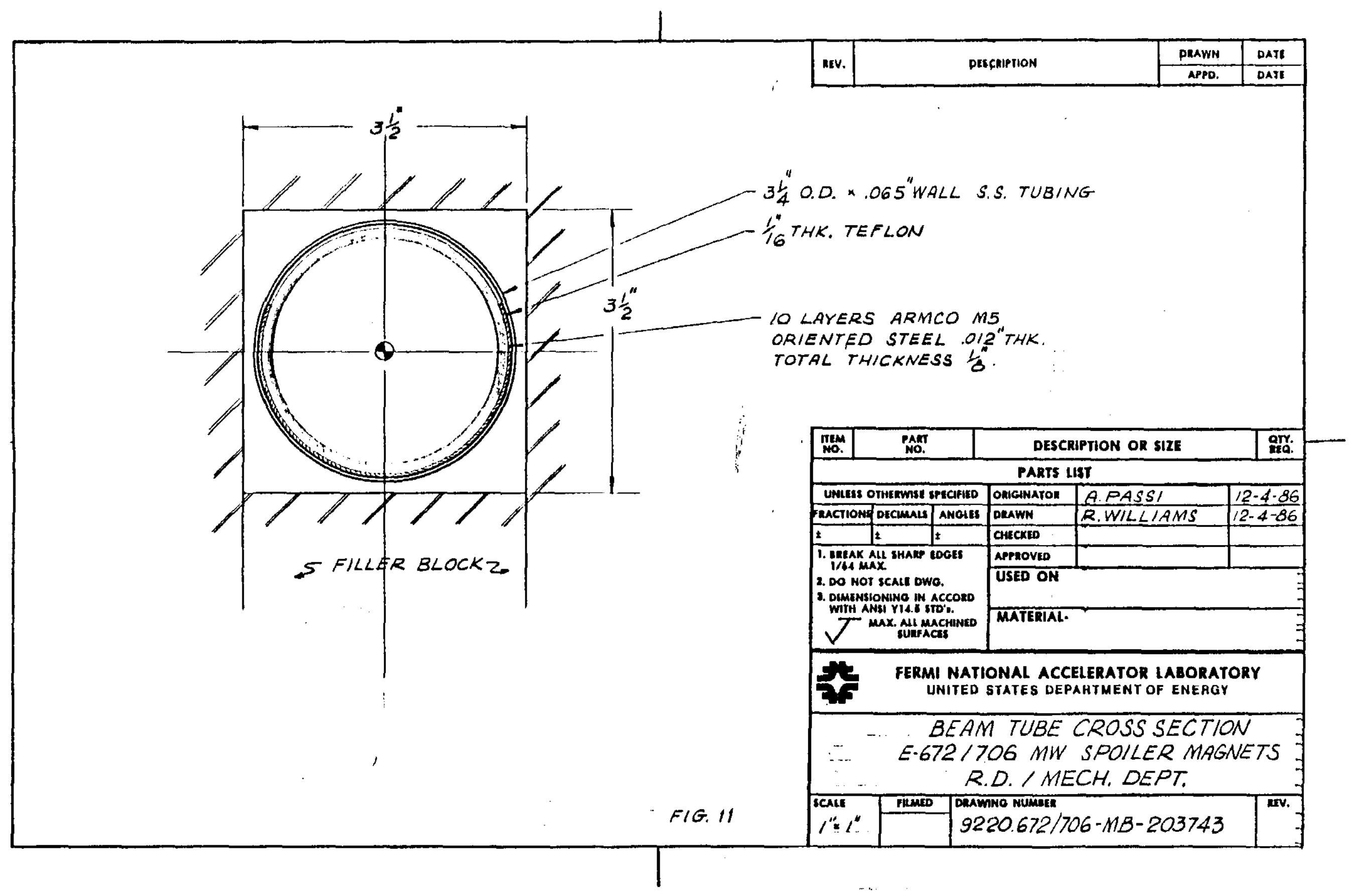




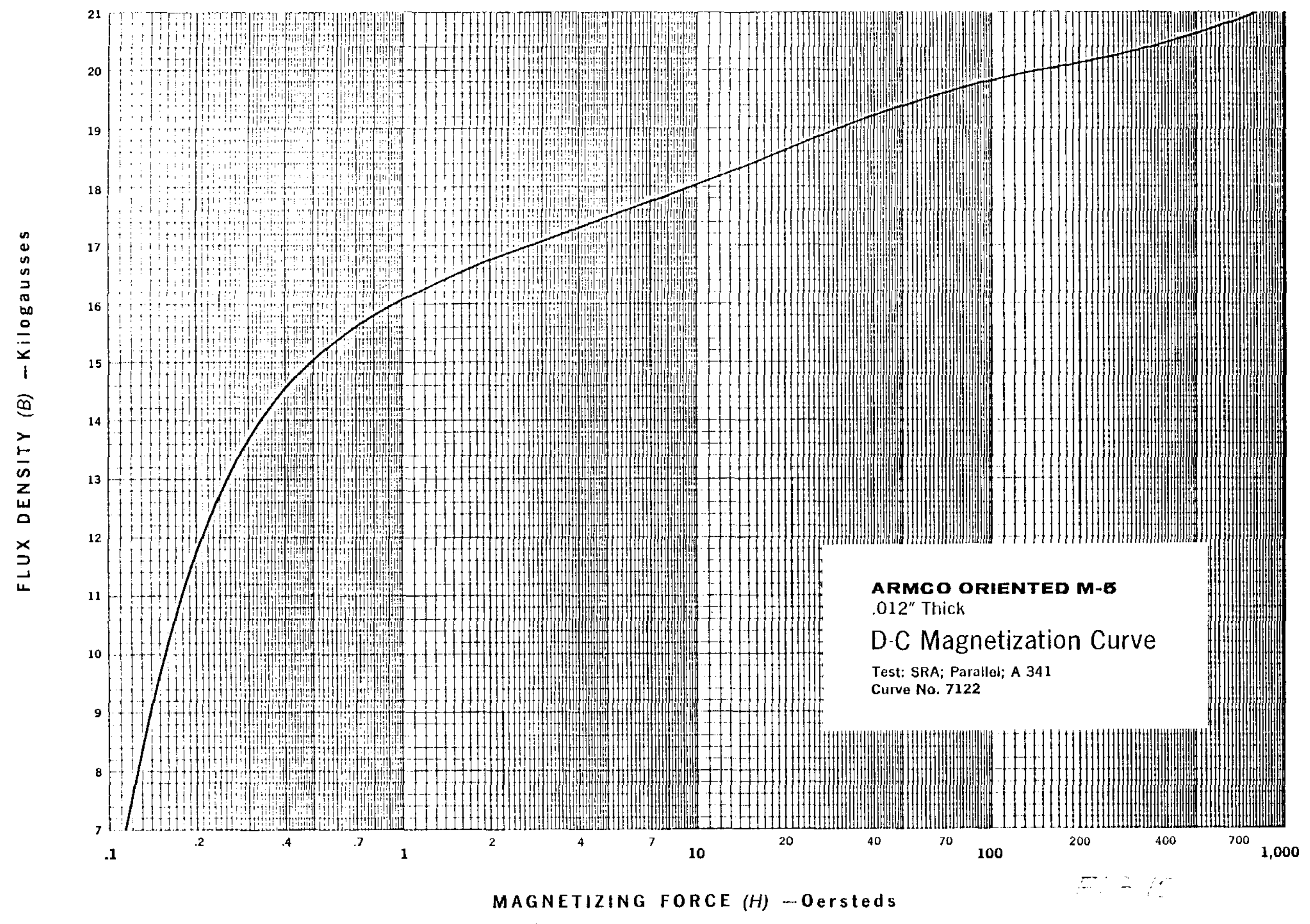




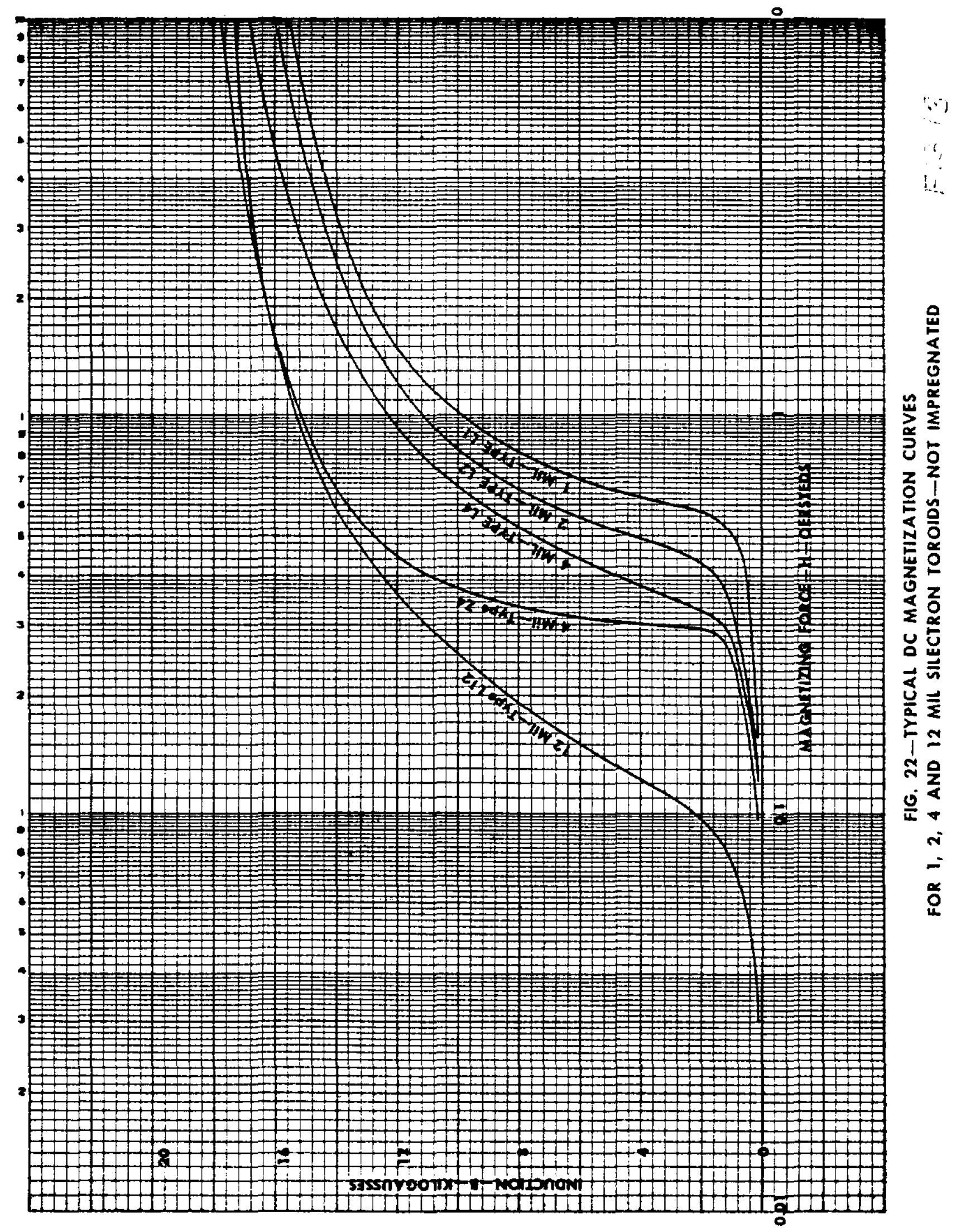

THE ARNOLD ENGINEERING COMPANY, MARENGO, ILLINOIS 